Research Article

\title{
Histopathological overview of cystoscopic bladder biopsies- A retrospective analysis
}

\author{
Suba G ${ }^{1}$, Gayathri $\mathbf{J}^{2}$, Jayaprakash $\mathbf{H T}^{3}$ \\ ${ }^{1}$ Dr. Suba G, Assistant Professor, ${ }^{2}$ Dr. Gayathri J, Post Graduate, ${ }^{3}$ Dr. Jayaprakash HT, Professor \& HOD, all authors are \\ affiliated with Department of Pathology, Dr. BRAMC, Bangalore, Karnataka, India.
}

Address for Correspondence: Dr. Suba G, Email: drsubag@gmail.com

\begin{abstract}
Background: Wide spectrums of nonneoplastic and neoplastic lesions are observed in urinary bladder. Correlation between clinical findings and histopathological features is essential in arriving at a correct diagnosis. This study is undertaken to analyse the pattern of lesions in cystoscopic bladder biopsies. Methods: This retrospective study consists of 70 cases of cystoscopic bladder biopsies carried out in the department of pathology. Clinical details of the patients were retrieved from the file. Specimens were processed routinely and stained with hematoxylin and eosin. Results: Three specimens out of 70 biopsies were inadequate for reporting. Of the remaining 67 cases, 38 were $(56.7 \%)$ neoplastic and $29(43.3 \%)$ were nonneoplastic lesions. The majority of the cases were seen in the age group of 41-50 yrs (29.9\%) with a male predominance $(73.1 \%)$. Urothelial tumours $(94.7 \%)$ were the predominant lesions observed under neoplastic category, of which invasive papillary urothelial carcinoma (80.6\%) was the most common subtype. Among nonneoplastic lesions, chronic nonspecific cystitis (51.7\%) was the commonest lesion noted Conclusion: There are wide ranges of lesions exist in the bladder. Urothelial tumours were the predominant lesions seen in cystoscopic biopsies followed by cystitis. Accurate diagnosis and early intervention is the key for better treatment outcome.
\end{abstract}

Keywords: Cystoscopy, Urothelial tumour, chronic nonspecific cystitis, Invasive papillary urothelial carcinoma, neoplastic

\section{Introduction}

Wide Spectrums of nonneoplastic and neoplastic lesions are common in urinary bladder, ranging from inflammatory conditions, infections, tumour like lesions, benign and malignant tumours. Bladder tumours are the second most common tumours of genitourinary tract. Developed countries show higher prevalence than developing countries [1]. The incidence of bladder tumours in men and women is $6 \%$ and $2 \%$ respectively [2]. About $90 \%$ of the tumours are urothelial cancers.

These tumours rank $5^{\text {th }}$ in the world and causes significant morbidity \& mortality [3]. In view of increasing trend in the occurrence of both neoplastic and nonneoplastic lesions of bladder, our study aims at evaluating the histomorphological features of cystoscopic biopsies. Cystoscopy helps in direct

Manuscript received: $8^{\text {th }}$ May 2017

Reviewed: $19^{\text {th }}$ May 2017

Author Corrected: $28^{\text {th }}$ May 2017

Accepted for Publication: $5^{\text {th }}$ June 2017 visualization of bladder and obtaining biopsies from suspicious areas. However, correlation is needed between urologic, radiologic findings and histopathological features to arrive at an accurate diagnosis.

\section{Objectives}

1. To study the histomorphological spectrum of non neoplastic and neoplastic lesions of bladder in cystoscopic biopsies.

2. To find out the incidence of various lesions of the bladder.

\section{Materials \& Methods}

This was a retrospective study conducted in the department of pathology. Cystoscopic biopsies of 70 cases were included in the study. Detailed clinical history and cystoscopic findings were retrieved from the patient record. All the specimens received were 


\section{Research Article}

fixed in $10 \%$ buffered neutral formalin for a period of 24 hrs. Entire tissue was submitted for processing. Paraffin embedded sections of $5 \mu$ size were cut and stained with Hematoxylin \& Eosin. Light microscopy was used for diagnosis. The malignant lesions were classified according to WHO/ISUP(2004) classification. Results were tabulated according to age \& sex.

Data source: Our study includes all the cystoscopic biopsies performed in the patients who visited surgery/urology department with urinary symptoms.
Inclusion Criteria- All the cystoscopic biopsies received in the department of pathology were included in the study.

Exclusion criteria-Unfixed autolysed specimens and biopsies which were inadequate for reporting were excluded from the study.

Statistical analysis-Microsoft office 2007 was used to generate tables. It is a descriptive study and the results are presented as mean and percentage.

\section{Results}

The majority of the cases were observed in the age group of 41-50 yrs (29.9\%) followed by 51-60 yrs (22.4\%). The age of the patients ranged from 9 yrs to 83 yrs in which $73.1 \%$ were males and $26.9 \%$ were females (Table 2). The common clinical presentation was hematuria followed by dysuria, frequency and suprapubic pain.

Of the 29 non neoplastic lesions, 15(51.7\%) were chronic nonspecific cystitis, 5(17.2\%) were follicular cystitis and $3(10.3 \%)$ were granulomatous cystitis of tubercular etiology. Other lesions like eosinophilic cystitis, hemorrhagic cystitis and vonbrunn's nest were observed in $2(6.9 \%), 1(3.5 \%)$ and 3(10.3\%) cases respectively. (Table 4) (Fig. 2a,b)

Table-1: Distribution of cases.

\begin{tabular}{|c|c|c|}
\hline Type of lesion & Number of cases & Percentage \\
\hline Non neoplastic & 29 & $43.3 \%$ \\
\hline Neoplastic & 38 & $56.7 \%$ \\
\hline Total & $\mathbf{6 7}$ & $\mathbf{1 0 0 \%}$ \\
\hline
\end{tabular}

Table-2: Age \& Sex wise distribution of cases.

\begin{tabular}{|c|c|c|c|}
\hline \multirow{2}{*}{ Age (in years) } & \multicolumn{2}{|c|}{ Number of cases (n=67) } & \multirow{2}{*}{ Percentage } \\
\cline { 2 - 3 } & Males & Females & $1.5 \%$ \\
\hline $0-10$ & 1 & 0 & $1.5 \%$ \\
\hline $11-20$ & 1 & 0 & $2.9 \%$ \\
\hline $21-30$ & 1 & 1 & $13.4 \%$ \\
\hline $31-40$ & 6 & 3 & $29.9 \%$ \\
\hline $41-50$ & 12 & 8 & $22.4 \%$ \\
\hline $51-60$ & 13 & 2 & $17.9 \%$ \\
\hline $61-70$ & 9 & 3 & $9 \%$ \\
\hline $71-80$ & 5 & 1 & $1.5 \%$ \\
\hline $81-90$ & 1 & 0 & \\
\hline
\end{tabular}

Neoplastic lesions were commonly seen from fourth to sixth decades of life. However the peak age of presentation was between 41-50 years. They were predominantly observed in male patients $81.6 \%(n=31)$. Urothelial tumours formed the largest group of the neoplastic category. They constituted $94.7 \%$ (36 cases) of all neoplastic lesions. The remaining 2 cases $(5.3 \%)$ were secondary adenocarcinomas. Among all urothelial tumours, invasive papillary urothelial carcinoma was the most common subtype accounting for 29 cases $(80.6 \%)$ with low grade comprising 8 cases and high grade 21 cases. Four of the high grade tumours showed squamous differentiation and one was clear cell variant of invasive urothelial carcinoma. Out of 5 (13.9\%) noninvasive papillary urothelial carcinomas, 4 were low grade lesions and one was high grade lesion. Papillary urothelial neoplasm of low malignant potential was observed in $2(5.6 \%)$ cases. (Table 3) (Fig 1a,b,c,d) 
Research Article

Table-3: Frequency of neoplastic lesions

\begin{tabular}{|c|c|c|}
\hline Type of lesion & No of cases( $\mathbf{n = 3 8})$ & Percentage \\
\hline PUNLUMP & 3 & $7.9 \%$ \\
\hline Non invasive papillary urothelial carcinoma & 11 & $28.9 \%$ \\
\hline Invasive urothelial carcinoma & 18 & $47.4 \%$ \\
\hline $\begin{array}{c}\text { Invasive urothelial carcinoma with squamous } \\
\text { differentiation }\end{array}$ & 4 & $10.5 \%$ \\
\hline Adenocarcinoma -metastatic & 2 & $5.3 \%$ \\
\hline
\end{tabular}

Table-4: Frequency of nonneoplastic lesions

\begin{tabular}{|c|c|c|}
\hline Type of lesion & No. of cases (N=29) & Percentage \\
\hline Chronic nonspecific cystitis & 15 & $51.7 \%$ \\
\hline Follicular cystitis & 5 & $17.2 \%$ \\
\hline Eosinophilic cystitis & 2 & $6.9 \%$ \\
\hline Granulomatous cystitis & 3 & $10.3 \%$ \\
\hline Hemorrhagic cystitis & 1 & $3.5 \%$ \\
\hline Von brunn's nest & 3 & $10.3 \%$ \\
\hline
\end{tabular}

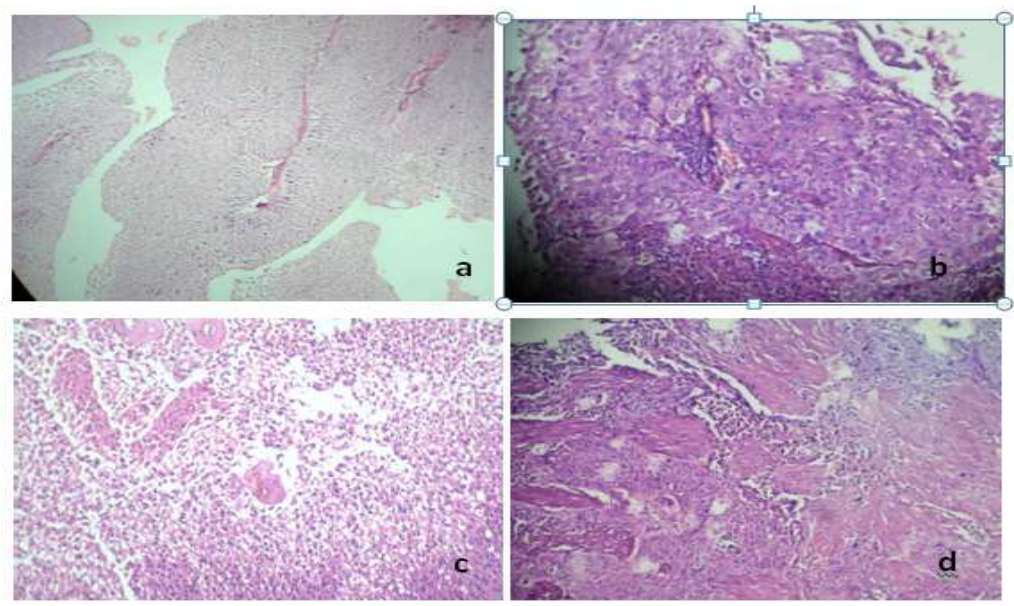

Fig.-1: Photomicrograph of neoplastic lesions of bladder: a) Non invasive high grade urothelial carcinoma b) Infiltrating papillary urothelial carcinoma-high grade c) Clear cell variant of urothelial carcinoma d) Detrusor muscle invasion in infiltrating urothelial carcinoma
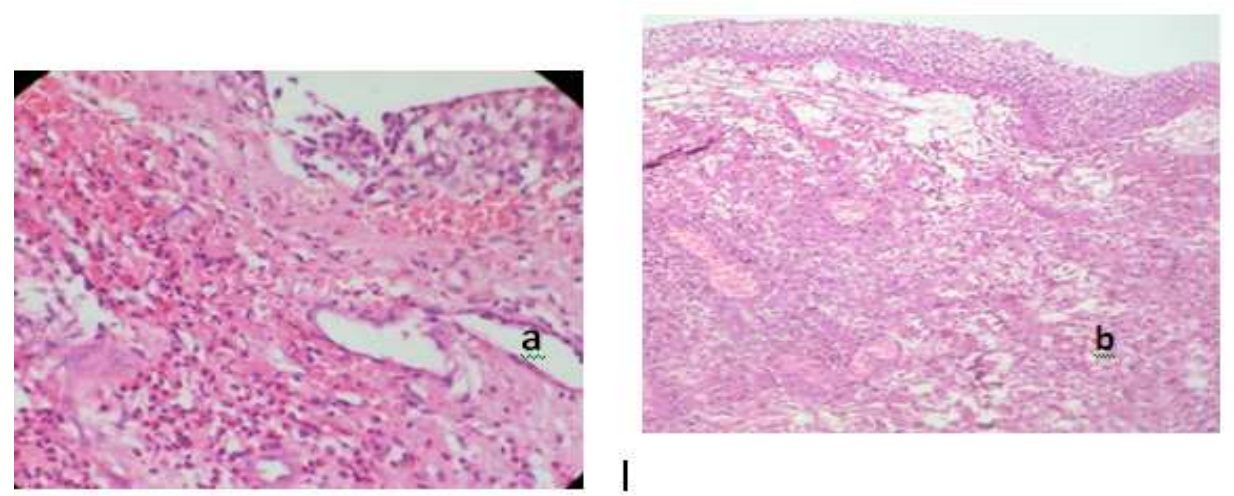

Fig.-2: Photomicrograph of non neoplastic lesions of bladder: a) Eosinophilic cystitis showing prominent infiltrate of eosinophils and edema in lamina propria. b) Mononuclear cell infiltrate with edema in the lamina propria in chronic nonspecific cystitis. 


\section{Discussion}

Bladder cancer is the most common urological malignancies and a major cause of morbidity and mortality. It is the fourth most common malignancy in men and eighth common in women in the western countries [4]. According to Indian cancer registry data in men, it is the ninth most common cancer [5]. It is more commonly seen in males with a male to female ratio of $8.9: 1[6]$. $90 \%$ of the bladder tumours are urothelial carcinoma. The median age of presentation is 69 years in men and 71years in women, though it can occur in any age group including children. It is very uncommon below 30 yrs and when occurs they have an excellent prognosis because they are mostly low grade tumours with early stage [7, 8].

The strongest environmental risk factor is smoking, followed by exposure to aromatic amines, hydrocarbons and schistosoma hematobium. Growing evidence suggest that genetic factors also play a significant role $[9,10]$. Bladder tumours classically present with painless hematuria. In our study $92 \%$ of the patients presented with hematuria. The common neoplastic lesion observed in our study was urothelial tumour (94.7\%). Among all the urothelial neoplasms invasive papillary urothelial tumour $(80.6 \%)$ was the most common subtype followed by non invasive papillary urothelial neoplasm (13.9\%) and PUNLUMP (5.6\%). This is comparable with other studies $[11,12,13]$.

Detrusor muscle was not seen in $27.6 \%$ of the biopsies of invasive tumours. In the remaining cases muscle invasion was identified in $42.9 \%$. Other authors observed $26 \%, 25 \%, 35.8 \%$ and $42.1 \%$ of muscle invasion respectively in their studies $[1,5,14,15]$. The incidence of squamous differentiation in urothelial carcinoma ranges from $11 \%$ to $60 \%$ of the cases. The prognostic significance of squamous differentiation is controversial. Some studies have found unfavourable response to chemotherapy and radiotherapy [16,17]. In the present study squamous differentiation was seen in $13.8 \%$ of cases of invasive tumours.

The clear cell variant of urothelial carcinoma is defined by the presence of either focal or extensive clear cell change with glycogen rich cytoplasm. It is important to differentiate from clear cell adenocarcinoma of bladder and metastatic renal \& prostatic carcinomas. It is more commonly observed in poorly differentiated urothelial carcinoma [18]. Clear cell variant was observed in one of the high grade urothelial tumours in our study. Primary adenocarcinoma of bladder is uncommon and accounts for $0.5 \%-2 \%$ of all bladder tumours. It is more common in males and more frequent in $6^{\text {th }}$ and $7^{\text {th }}$ decades of life. Morphologically it shows varying growth patterns including enteric, mucinous, signet ring cell, clear cell and mixed type. Metastatic adenocarcinoma is commoner than primary tumours $[19,20,21]$. In this study, we reported 2 cases of secondary adenocarcinoma in elderly males. Both the patients were known case of carcinoma prostate underwent surgery 5 and 7 years back respectively.

The most common non neoplastic lesion in our study was chronic nonspecific cystitis comprising $51.7 \%$ of cases with the age range of 19-75 yrs. This is in accordance with other studies [11,13,22]. Microscopy revealed chronic inflammatory infiltrate associated with edema and congestion in lamina propria. Some of the cases showed partial ulceration of the overlying urothelium.

In the present study granulomatous cystitis was found in $10.3 \%$ of all non neoplastic lesions with a male predominance. Various infections and iatrogenic conditions can lead to granulomatous cystitis. However TB remains the most frequent cause in developing countries like India. It is frequently secondary to renal tuberculosis. Men are more commonly affected than women with a mean age of 40.7 years. The lesions are most commonly found near ureteric orifices [23,24,25].

Eosinophilic cystitis is an uncommon entity of bladder, reported in all ages and both sexes equally. Though the exact etiology is unclear it has been associated with allergy, asthma and autoimmune conditions. Microscopy shows dense transmural infiltrate of eosinophils with variable stromal edema often associated with intramural fibrosis [26, 27, 28, 29]. In current study eosinophilic cystitis was observed in $6.9 \%$ of all cases.

There were 3 cases ( $10.3 \%$ of all nonneoplastic lesions) of von brunn nest seen in our study. It is characterised by the presence of solid nests of urothelium in lamina propria with no continuity to the overlying mucosa. Florid von brunn nest resembles nested variant of urothelial carcinoma which may be a diagnostic concern [30, 31]. 


\section{Conclusion}

Cystoscopic biopsies play an important role in early diagnosis of bladder tumours. Malignant tumours were the most common bladder lesions followed by inflammatory conditions. Urothelial tumours are the most common malignant lesions and observed mainly in middle aged males. Chronic nonspecific cystitis is the commonest nonneoplastic lesion encountered in routine practice. Accurate diagnosis and early intervention is the key for better treatment outcome.

Funding: Nil, Conflict of interest: None initiated, Permission from IRB: Yes

\section{References}

1. Pudasaini S, Subedi N, Prasad KB, Rauniyar SK, Joshi BR, Bhomi KK. Cystoscopic bladder biopsies: a histopathological study. Nepal Med Coll J. 2014 Sep;16 (1): 9-12.

2. Srikousthubha, Sukesh, Raghuveer CV, Hingle S. Profile of Lesions in Cystoscopic Bladder Biopsies -A Histopathological Study. J Clin Diagn Res 2013 Aug; 7 (8): 1609-12.

3. Stepan A, Simionescu C, Margaritescu C, Ciurea R. Histopathological study of the urothelial bladder carcinomas. Current Health Sci J 2013 Jul -Sep; 39(3): 147-150.

4. Kirkali Z, Chan T, Manoharan M, Algaba F, Busch C, Cheng L, Kiemeney L, Kriegmair M, Montironi R, Murphy WM, Sesterhenn IA, Tachibana M, Weider J. Bladder cancer: epidemiology, staging and grading, and diagnosis. Urology. 2005 Dec;66(6 Suppl 1):4-34.

5. Gupta P, Jain M, Kapoor R, Muruganandham K, Srivastava A, Mandhani A. Impact of age and gender on the clinicopathological characteristics of bladder cancer. Indian J Urol. 2009 Apr;25(2):207-10. doi: 10.4103/0970-1591.52916.

6. T. B. Yuvaraja, Santosh Waigankar, Ganesh Bakshi, and Gagan Prakash Genitourinary cancers: Summary of Indian data. South Asian J Cancer. 2016 Jul-Sep; 5(3): 122-124.

7. M. Nomikos, A. Pappas, M.E. Kopaka, S. Tzoulakis, I. Volonakis, G. Stavrakakis, et al. Urothelial carcinoma of the urinary bladder in young adults: presentation, clinical behavior and outcome. Adv Urol,2011(2011): 480738 .
8. Stanton ML, Xiao L, Czerniak BA, Guo CC. Urothelial tumors of the urinary bladder in young patients: a clinicopathologic study of 59 cases. Arch Pathol Lab Med. 2013 Oct;137(10):1337-41. doi: 10. 5858 /arpa.2012-0322-OA.

9. Burger M, Catto JW, Dalbagni G, Grossman HB, Herr H, Karakiewicz P, Kassouf W, Kiemeney LA, La Vecchia C, Shariat S, Lotan Y. Epidemiology and risk factors of urothelial bladder cancer. Eur Urol. 2013 Feb;63(2):234-41. doi: 10.1016/j.eururo.2012.07.033. Epub 2012 Jul 25.

10. Mostafa MH, Sheweita SA, O'Connor PJ. Relationship between schistosomiasis and bladder cancer. Clin Microbiol Rev. 1999 Jan; 12 (1): 97-111.

11. C. Aparna, M.D., Rayapa Reddy Thumma, C Padmavathi Devi, S V R L Jyothi Vanapalli, T D N Mounika. Histological spectrum of urothelial lesions experience of a single tertiary care institute. International Journal of Contemporary Medical Research 2016 Jun; 3(6):1731-1733.

12. Goyal VK, Vyas SP, Kothari DC. Spectrum of Lesions in Urinary Bladder Biopsies: Histopathological Study. Int J Dent Med Res 2015 Mar-Apr; 1 (6): 42-46.

13. Mahesh KU, Yelikar BR. Spectrum of lesions in cystoscopic bladder biopsies- A histopathological study. Al Ameen J Med Sci. 2012; 5(2):132-6.

14. Vaidya S, Lakhey M, K C S, Hirachand S. Urothelial tumours of the urinary bladder: a histopathological study of cystoscopic biopsies. JNMA J Nepal Med Assoc. 2013 Jul-Sep;52(191):475-8.

15. Laishram RS, Kipgen P, Laishram S, Khuraijam S, Sharma DC. Urothelial tumors of the urinary bladder in Manipur: a histopathological perspective. Asian Pac J Cancer Prev. 2012;13(6):2477-9.

16. Antunes AA, Nesrallah LJ, Dall'Oglio MF, Maluf CE, Camara C, Leite KR, Srougi M. The role of squamous differentiation in patients with transitional cell carcinoma of the bladder treated with radical cystectomy. Int Braz J Urol. 2007 May-Jun;33(3):33945; discussion 346. 
17. Lopez-Beltran A, Requena MJ, Alvarez-Kindelan J, et al. Squamous differentiation in primary urothelial carcinoma of the urinary tract as seen by MAC387 immunohistochemistry. J Clin Pathol 2007 Mar; 60(3): 332-335.

18. Eble J.N., Sauter G., Epstein J.I., Sesterhenn I.A. (Eds.): World Health Organization Classification of Tumours. Pathology and Genetics of Tumours of the Urinary System and Male Genital Organs. IARC Press: Lyon 2004.

19. Dadhania V, Czerniak $\mathrm{B}^{1}$, Guo CC. Adenocarcinoma of the urinary bladder. Am J Clin Exp Urol. 2015 Aug 8;3(2):51-63. eCollection 2015.

20. Kapur P, Lotan Y, King E, Kabbani W, Mitra AP, Mosbah A, Abol-Enein H, Ghoneim M, Youssef RF. Primary adenocarcinoma of the urinary bladder: value of cell cycle biomarkers. Am J Clin Pathol. 2011 Jun; 135(6):822-30.doi:10.1309/AJCP76 KUVOTBKQ RY.

21. Roy S, Parwani AV. Adenocarcinoma of the urinary bladder. Arch Pathol Lab Med. 2011 Dec;135(12): 1601-5. doi: 10.5858/arpa.2009-0713-RS.

22. Shruthi.H.P, Rangaswamy.R. Spectrum of Lesions in Urinary Bladder Biopsies - A Histopathological Study. IJHSR. 2015; 5(5): 144-152.

23. Ali MY, Fattah SA, Islam MM, Haque MM, Biswas AK , Hossain MA. Urinary Bladder Tuberculosis - A Case Report. Faridpur Med. Coll. J. 2010; 5(2):66-68.

24. Figueiredo A., Lucon A. Urogenital tuberculosis: update and review of 8961 cases from the world literature. Nat Rev Urol 2008 Summer; 10(3): 207217.

25. Zarrabi AD, Heyns CF. Tuberculosis of the urinary tract and male genitalia-a diagnostic challenge for the family practitioner. SA Fam Pract 2009 Sep-Oct; 51(5): 388-92.

26. Kumar S, Sharma V, Ganesamoni R, Singh S. Eosinophilic cystitis mimicking tuberculosis: An analysis of five cases with review of literature. Urology Annals. 2013; 5(1):50-52.

27. Popescu OE, Landas SK, Haas GP. The spectrum of eosinophilic cystitis in males: case series and literature review. Arch Pathol Lab Med. 2009 Feb;133(2):289-94. doi: 10.1043/1543-2165-133.2.289.

28. Chia D. Eosinophilic cystitis and haematuria: Case report of a rare disease and common presentation. Int $\mathrm{J}$ Surg Case Rep. 2016;24:43-5. doi: 10.1016/j.ijscr. 2016.04. 055. Epub 2016 May 6.

29. Hellstrom HR, Davis BK, Shonnard JW. Eosinophilic cystitis. A study of 16 cases. Am J Clin Pathol. 1979 Nov;72(5):777-84.

30. Young RH. Tumor-like lesions of the urinary bladder. Mod Pathol. 2009 Jun;22 Suppl 2:S37-52. doi: 10.1038/modpathol.2008.201.

31. Volmar KE, Chan TY, De Marzo AM, Epstein JI. Florid von Brunn nests mimicking urothelial carcinoma: a morphologic and immunohistochemical comparison to the nested variant of urothelial carcinoma. Am J Surg Pathol. 2003 Sep;27(9):1243-52.

\section{How to cite this article?}

Suba G, Gayathri J, Jayaprakash HT. Histopathological overview of cystoscopic bladder biopsies- A retrospective analysis.Trop J Path Micro 2017;3(2):229-234.doi: 10.17511/jopm.2017.i2.27. 